\title{
Fibroadenoma in Blacks
}

\section{Raphael Odobueze Egejuru', Ikechukwu Godfrey Nnadi1 ${ }^{*}$, Okechukwu Nwabugo Duru²}

${ }^{1}$ Department of Histopathology, FMC, Owerri, Nigeria

${ }^{2}$ Department of Surgery, FMC, Owerri, Nigeria

Email: *godheniknnd@yahoo.com

How to cite this paper: Egejuru, R.O., Nnadi, I.G. and Duru, O.N. (2017) Fibroadenoma in Blacks. Health, 9, 1475-1481. https://doi.org/10.4236/health.2017.911108

Received: August 12, 2017

Accepted: October 15, 2017

Published: October 18, 2017

Copyright (c) 2017 by authors and Scientific Research Publishing Inc. This work is licensed under the Creative Commons Attribution International License (CC BY 4.0).

http://creativecommons.org/licenses/by/4.0/

\begin{abstract}
Background: Fibroadenoma is the commonest benign tumour of the breast affecting the majority of young females below the age of thirty in our environment. It is a source of concern and psychological problems in females requiring medical attention in our hospitals. Aim: This study describes the clinicopathologic characteristics of fibroadenoma in Eastern Nigerian Igbo females. Methodology: The archives of the Department of Pathology Federal Medical Centre, Owerri was used for the data collection and analyzed using simple statistics. Results: 504 fibroadenomas were analyzed. The average size was $1.99 \mathrm{~cm}$ with a range of $0.5 \mathrm{~cm}$ to $18 \mathrm{~cm}$. The average age of the patients was $22.6 \pm 6.7$ years with a range of 9 to 60 years. The peak age of incidence was in the $11-20(44.64 \%)$ age group followed closely by the $21-30(43.45 \%)$ age group. The ratio of involvement of the left to the right breast was 1:1.2. Fibroadenoma was $18 \%$ multiple and $10.7 \%$ bilateral. $5.3 \%$ (27), $0.6 \%$ (3), and $0.2 \%$ ( 1 ) of the cases were giant, complex fibroadenoma and malignant breast disease in fibroadenoma respectively. Conclusion: This study has provided insights into the clinicopathologic characteristics of fibroadenoma among Nigerian Igbos and calls for more research in this area in other parts Nigeria and elsewhere.
\end{abstract}

\section{Keywords}

Fibroadenoma, Blacks, Owerri

\section{Introduction}

Fibroadenoma is the commonest benign tumor of the breast among young women of Africa descent [1]. Several reports indicated that fibroadenoma is the commonest benign breast disease and the commonest cause of surgical outpatient visits by adolescent and young adult females [2]-[7]. It accounts for $68 \%$ of all breast masses and $44 \%-94 \%$ of all biopsied breast lesions. Fibroadenomas 
can range from asymptomatic masses to painful and rapidly growing tumors that can cause significant esthetic distortions of the breast [7]. The presence of a lump in the breast is a cause of great anxiety, apprehension, psychosocial morbidity and uncertainty to most patients [2] [7]. This may reflect the increasing public awareness of breast cancer which is at present the most common female malignancy worldwide [2].

This study describes the clinicopathologic characteristics of fibroadenoma in Eastern Nigerian Igbo females.

\section{Methodology}

This is a retrospective study of fibroadenoma among females in Federal Medical Centre, Owerri [8] [9], Imo State, Nigeria. The surgical daybooks, the histology request and report forms were carefully perused for the demographic, clinical and histopathologic parameters of the patients whose specimens were received in the Department of Pathology, Federal Medical Centre, Owerri between April 2010 and March 2016. The histology reports were reviewed along with the histology slides and the histological diagnosis and variants of fibroadenoma were recorded. The samples with complete records and those whose fresh histology slides could be made by sectioning $(2-3 \mu \mathrm{m})$ the paraffin-embedded tissue blocks were included in the study. The data were analyzed using simple statistics.

\section{Results}

A total of 504 biopsies of fibroadenoma of the breast were collected in the Department of Pathology, Federal Medical Center Owerri between April 2010 and March 2016. The average ages of the patients were $22.6 \pm 6.7$ years with a range of 9 to 60 years. The peak age of incidence was in the $11-20$ (44.64\%) age groups followed closely by the $21-30(43.45 \%)$ age groups. This is shown in $\mathrm{Ta}$ ble 1 below. The average size of the tumours was $1.99 \mathrm{~cm}$ with a range of 0.5 to $18 \mathrm{~cm}$. The largest measured $18 \times 17 \times 10 \mathrm{~cm}$ and weighed $1.5 \mathrm{~kg} .5 .3 \%(27)$ and $0.6 \%$ (3) of the cases were giant and complex fibroadenoma respectively. The relative frequencies of the sizes of the fibroadenoma is illustrated in Table 2.

Table 1. Showing the distribution of fibroadenoma among different age groups.

\begin{tabular}{cccc}
\hline $\mathbf{s} / \mathbf{n}^{*}$ & Age groups & Freq $^{*}$ & $\%$ \\
\hline $\mathbf{1}$ & $1-10$ & 2 & 0.39 \\
$\mathbf{2}$ & $11-20$ & 225 & 44.64 \\
$\mathbf{3}$ & $21-30$ & 219 & 43.45 \\
$\mathbf{4}$ & $31-40$ & 43 & 8.53 \\
$\mathbf{5}$ & $41-50$ & 11 & 2.18 \\
$\mathbf{6}$ & $51-60$ & 6 & 1.19 \\
Total & & 504 & 100.00 \\
\hline
\end{tabular}

${ }^{*}(\mathrm{~s} / \mathrm{n}=$ Serial number, Freq $=$ frequency $)$. 
There is a slight predilection for the right breast giving a left to right ratio of 1:1.2. Multiple lumps occurred in 91 cases (18\%), with a slightly higher number of multiple lumps in left (9.5\%) breasts. The range of multiple lumps was 2 to 8 . Bilateral fibroadenoma was present in 54 cases (10.7\%) and 2.8\% (14 cases) were associated with fibrocystic changes, $0.4 \%$ with tubular adenoma, sclerosing adenosis and chronic mastitis respectively. Association with benign phylloides and intraductal papilloma occurred in $0.2 \%$ (1) of cases respectively. Fibroadenocarcinoma was present in one (0.2\%) sample. Figure 1 is a pie chart illustrating the relative frequency among multiple, giant, bilateral, complex and fibroadenocarcinoma.

\section{Discussion}

In this study, a total of 504 biopsies of fibroadenoma of the breast were analyzed.

Table 2. Shows the relative frequency of different sizes of fibroadenoma.

\begin{tabular}{cccc}
\hline $\mathbf{s} / \mathbf{n}$ & Size $(\mathrm{cm})$ & Freq & $\%$ \\
\hline $\mathbf{1}$ & $0.0-1.0$ & 53 & 10.51 \\
2 & $1.1-2.0$ & 170 & 33.73 \\
$\mathbf{3}$ & $2.1-3.0$ & 137 & 27.18 \\
$\mathbf{4}$ & $3.1-4.0$ & 78 & 15.47 \\
$\mathbf{5}$ & $4.1-5.0$ & 40 & 7.93 \\
$\mathbf{6}$ & $>5.1$ & 27 & 5.35 \\
Total & & 504 & 100 \\
\hline
\end{tabular}

$*(s / \mathrm{n}=$ Serial number, Freq $=$ frequency $)$.

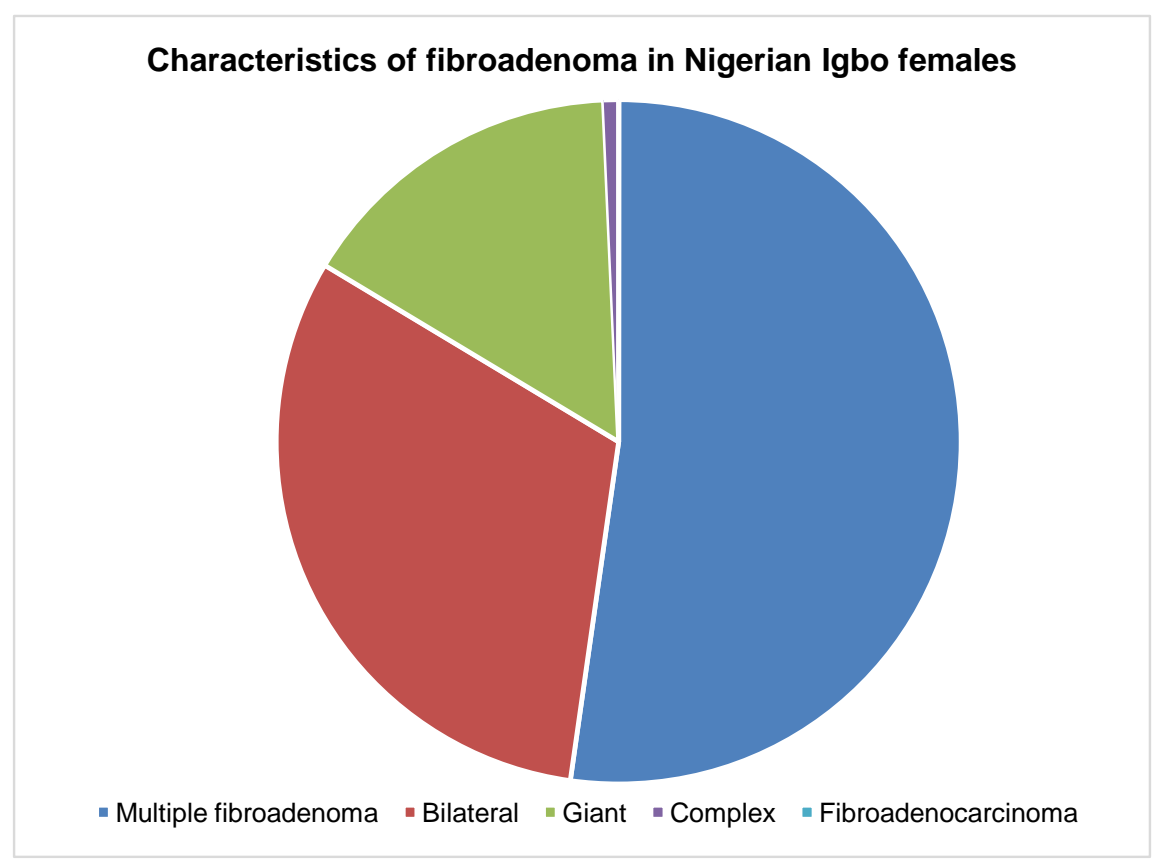

Figure 1. A pie chart showing the distribution of multiple, giant, bilateral, complex fibroadenoma and fibroadenocarcinoma. 
The average age of the patients was $22.6 \pm 6.7$ years. The peak age of incidence was in the $11-20(44.64 \%)$ age group followed closely by the 21 - $30(43.45 \%)$ age group. These findings agreed with studies from Benin City, Enugu, Maiduguri, Ghana, and India [1] [2] [3] [10] [11]. However, the mean age of patients diagnosed with fibroadenoma in Enugu, India, and Kingdom of Saudi Arabia were 18, 27 and 28.69 years respectively [6] [11] [12]. The age range in this study was 9 to 60 years. Similar observations were made by Alagar et al. [11] in Tamilnadu, India. Nonetheless, most other studies reported different age ranges [1] [3] [13] [14]. Though our study showed the youngest age to be 9 years, it is noteworthy that fibroadenoma can occur below the age of two years [15] [16].

In this study, there was a slight predilection for the right breast giving a left to right ratio of 1:1.2. This agreed with reports from India [5] [11]. However observation from Enugu, Eastern Nigeria demonstrated a slightly increased involvement of the left breast [12].

We observed that the average size of the tumours was $1.99 \mathrm{~cm}$ with a range of 0.5 to $18 \mathrm{~cm}$. The largest measured $18 \times 17 \times 10 \mathrm{~cm}$ and weighed $1.5 \mathrm{~kg}$. The average size of the tumours was quite lower than reports from Enugu, Ghana, and India [1] [12] [14]. Furthermore, Alagar et al. [11] reported that the range of sizes of the fibroadenomas in their study was 1 to $9 \mathrm{~cm}$.

We observed that thirty-eight cases $(7.5 \%)$ were giant fibroadenoma with an average size of $8.2 \mathrm{~cm}$ and mean age of 17.87 years. About $65.6 \%$ occurred in patients below the age of twenty years and the largest was found in a 12-year-old girl. In a multicentre systematic review in the USA, Sosin et al. [17] reported that the mean age of patients diagnosed with giant fibroadenoma was 16.7 years and the average size of the tumours was $11.2 \mathrm{~cm}$. In addition, Musio et al. [18] reported that these giant fibroadenomas are rare and occur mainly in adolescent and young adult black females. Reports from India demonstrated variable observations. Alagar and Kumar et al. [5] [11] reported that giant fibroadenoma constituted $1.5 \%$ and $18.75 \%$ respectively in their studies. We also observed that complex fibroadenoma made up $0.6 \%$ (3) of cases and occurred in patients with average age of 24 years. In Israel, Sklair-Levy et al. [19] reported that $15.7 \%$ of fibroadenoma were of the complex type.

Multiple lumps occurred in 91 cases (18\%) of the cases with a slightly higher involvement of the left $(9.5 \%)$ breasts. The range of multiple lumps was 2 to 8 . This observation agreed with finding in Ghana, a neighboring West African country [1]. However, this is markedly higher than reports from India, where multiple fibroadenomas constituted $0.7 \%$ [5]. Though in this study the range of a multiple tumour was $2-8$, Zhang et al. [20] reported that multiplicity of lumps could be as high as 20 to 29 lumps in a patient.

Furthermore, we observed that Fibroadenoma was bilateral in 54 (10.7\%) cases. This occurred in $54.38 \%$ of patients 20 years and above. Other reports showed that bilateral fibroadenoma occurred in $10.9 \%, 12.5 \%, 12.63 \%, 16.1 \%$ in Enugu, India, and Ghana respectively [1] [5] [11] [12]. In addition, this study 
revealed that $2.8 \%$ ( 14 cases) of fibroadenoma were coexisting with fibrocystic changes, $0.4 \%$ with tubular adenoma, sclerosing adenosis and chronic mastitis respectively. Association with benign phylloides and intraductal papilloma occurred in $0.2 \%$ (1) of cases respectively. There is a paucity of literature on the association or co-existence of fibroadenoma and other benign breast lesions. However, Komachi and Bjerregaard et al. [21] [22] reported that fibroadenoma was found in classic tubular adenoma without a transition zone between the two pathological entities in Japan and Kenya respectively. Similar associations of fibroadenoma with intraductal papilloma, [23] [24] and intraductal phylloides tumour [25] were reported in Italy, Australia and Croatia respectively.

Several studies have demonstrated the presence of invasive breast carcinomas within or in the tissues adjacent to fibroadenomas [26] [27] [28] [29]. In this study, a single $(0.2 \%)$ case of invasive ductal carcinoma was found within a fibroadenoma in a 24-year-old patient. Hua et al. [27] reported that though the malignant transformation of fibroadenoma is very rare, the incidence of breast carcinoma within fibroadenoma is estimated at $0.1 \%$ to $0.3 \%$ and fibroadenoma may be a risk factor for malignant breast disease in the middle age. Similarly, the risk of breast carcinoma is $2.17,3.1$ and 3.88 times higher in patients with simple, complex and benign proliferative diseases adjacent to fibroadenoma respectively [30]. In our study, the age of our patient appears to be very low compared to mean age of 46.9 years reported by $\mathrm{Wu}$ et al. [31] in Taiwan. Nonetheless, Nugochi et al. [32] reported that both the epithelial and stromal components of fibroadenoma were polyclonal and may be visualized as hyperplastic lesion than a neoplasm. In addition, McCulloch et al. [33] demonstrated that genetic alterations such as microsatellite instability (MSI) and loss of heterozygosity (LOH) do not occur in fibroadenoma or may occur at very low rates of $1 \%$ and $1.8 \%$ respectively. However, about $0.15 \%$ of invasive breast tumours arise from epithelial cells of fibroadenoma [26].

\section{Ethical Considerations}

Ethical clearance for this study was obtained from Research ethics committee Federal Medical Centre Owerri.

\section{Limitations of the Study}

The most important limitation of this study was the incomplete records observed during the data collection which lead to rejection of some cases of fibroadenoma in the departmental archives. The authors were also compelled to out-of-pocket spending to ensure the research was given adequate funding as there was no grant attracted for it.

\section{References}

[1] Bewtra, C. (2009) Fibroadenoma in Women in Ghana. The Pan African Medical Journal, 2, 1-5. 
[2] Olu-Eddo, A.N. and Ugiagbe, E.E. (2011) Benign Breast Lesions in an African Population: A 25-Year Histopathological Review of 1864 Cases. Nigerian Medical Journal, 52, 211-216. https://doi.org/10.4103/0300-1652.93790

[3] Anyikam, A., Nzegwu, M.A., Ozumba, B.C., Okoye, I. and Olusina, D.B. (2008) Benign Breast Lesion in Eastern Nigeria. Saudi Medical Journal, 29, 241-244.

[4] Echejoh, G., Dzuachi, D. and Jenrola, A. (2011) Histopathologic Analysis of Benign Breast Diseases in Makurdi, North Central Nigeria. International Journal of Medical Sciences, 3, 125-128.

[5] Kumar, M., Ray, K., Harode, S. and Wagh, D.D. (2010) The Pattern of Benign Breast Diseases in Rural Hospital in India. ECAJS, 15, 59-64.

[6] Jamal, A.A. (2001) Pattern of Breast Diseases in a Teaching Hospital in Jeddah, Saudi Arabia. Saudi Medical Journal, 22, 110-113.

[7] Lee, M. and Soltanian, H.T. (2015) Breast Fibroadenomas in Adolescents: Current Perspectives. Adolescent Health, Medicine and Therapeutics, 6, 159-163.

[8] Federal Republic of Nigeria Official Gazette (2007) Legal Notice on Publication of the Details of the Breakdown of the National and State Provisional Totals 2006 Census.

[9] Acholonu, A.D.W. (2008) Water Quality Studies of Nworie River in Owerri, Nigeria. Mississippi Academy of Sciences.

[10] Nuhu, A., Aliyu, S. and Musa, A.B. (2014) Management of Breast Lumps in Maiduguri, Nigeria. Sahel Medical Journal, 17, 50-53. https://doi.org/10.4103/1118-8561.134475

[11] Alagar, S.R. and Purushothaman, R. (2015) An Analytical Study on Fibroadenoma of the Breast. CIB Tech Journal of Surgery, 4, 40-45.

[12] Wilson, O. (2003) Breast Fibroadenoma in Teenage Females. The Turkish Journal of Pediatrics, 45, 326-328.

[13] Chalya, P.L., Manyama, M., Rambau, P.F., Kapesa, A., Nballaba, S.E. and Masalu, N. (2016) Clinicopathological Pattern of Benign Breast Diseases among Female Patients at a Tertiary Health Institution in Tanzania. Tanzania Journal of Health Research, 18.

[14] Vijaykumar, A., Ajitha, M.B., Shivaswamy, B.S. and Srinivasan, N. (2012) A Systematic Study on Fibroadenoma of the Breast. European Journal of Surgical Sciences, 3, 80-85.

[15] Fernández, C.G., Martín, C.G., Gracia, B.R., Calvo de Mora, A.J. and Lassaletta, G.L. (1998) Fibroadenoma of the Breast in a 17-Month-Old Girl. Cirugia Pediatrica, 11, 120-122.

[16] Shi, A., Li, S., Xu, N., Nie, G., Li, X., Zhang, T., et al. (2011) Clinical Features and Prognosis of a Unilateral Fibroadenoma of the Breast in a 16-Month-Old Female. Japanese Journal of Clinical Oncology, 41, 260-264. https://doi.org/10.1093/jjco/hyq181

[17] Sosin, M., Pulcrano, M., Feldman, E.D., Patel, K.M., Nahabedian, M.Y., Weissler, J.M., et al. (2015) Giant Juvenile Fibroadenoma: A Systematic Review with Diagnostic and Treatment Recommendations. Gland Surgery, 4, 312-321.

[18] Musio, F., Mozingo, D. and Otchy, D.P. (1991) Multiple, Giant Fibroadenoma. The American Surgeon, 57, 438-441.

[19] Sklair-Levy, M., Sella, T., Alweiss, T., Craciun, I., Libson, E. and Mally, B. (2008) Incidence and Management of Complex Fibroadenomas. American Journal of Roentgenology, 190, 214-218. https://doi.org/10.2214/AJR.07.2330 
[20] Zhang, R., Bevan, S., Sun, P., Lu, J.Z. and Peng, Y. (2012) Unusual Presentation of Multiple Fibroadenomas in Bilateral Breasts and Axillary Accessory Breast. Breast Cancer. Basic and Clinical Research, 6, 95-99.

[21] Komaki, K., Morimoto, T., Mori, T., Sasa, M., Oshimo, K., Monden, Y., et al. (1992) A Rare Case of Fibroadenomain a Tubular Adenoma of the Breast. Surgery Today, 22, 163-165. https://doi.org/10.1007/BF00311343

[22] Bjerregaard, B. and Kung'u, A (1992) Benign Breast Lesions in Kenya: A Histological Study. East African Medical Journal, 69, 231-235.

[23] Alessandrini, L., Gobbi, D., Zanon, G.F., Dall'Igna, P., Cecchetto, G. and Alaggio, R. (2013) Concurrent Fibroadenoma and Intraductal Papilloma-A Recurring Complex Lesion in a Premenarcheal Girl. Pathology, Research and Practice, 209, 120-123.

[24] Cummings, M.C., da Silva, L., Papadimos, D.J. and Lakhani, S.R. (2009) Fibroadenoma and Intraduct Papilloma-A Common Pathogenesis? Virchows Archiv, 455, 271-275. https://doi.org/10.1007/s00428-009-0817-8

[25] Bezić, J. (2010) Intraductal Fibroadenoma and Intraductal Phyllodes Tumour-A Part of the Spectrum of the Breast Ductal Adenoma? Virchows Archiv, 456, 105-106. https://doi.org/10.1007/s00428-009-0870-3

[26] Morelli, A., Díaz, L., Vighi, S., Romeo, L. and Gómez Rueda, N. (1989) Carcinoma and Fibroadenoma of the Breast. Medicina (B Aires), 49, 583-588.

[27] Abe, H., Hanasawa, K., Naitoh, H., Endo, Y., Tani, T. and Kushima, R. (2004) Invasive Ductal Carcinoma within a Fibroadenoma of the Breast. International Journal of Clinical Oncology, 9, 334-338. https://doi.org/10.1007/s10147-004-0401-9

[28] Wu, Y., Chen, S., Chen, C., Kuo, Y., Tseng, L. and Chen, D. (2014) Breast Cancer Arising within Fibroadenoma: Collective Analysis of Case Reports in the Literature and Hints on Treatment Policy. World Journal of Surgical Oncology, 12, 335. https://doi.org/10.1186/1477-7819-12-335

[29] Hashimoto, T., Toyono, M. and Fuyama, S. (2014) A Case of Mammary Pagetoid Carcinoma with a Coexisting Fibroadenoma. Austin Journal of Surgery, 1, 1043.

[30] Hua, B., Xu, J., Jiang, L. and Wang, Z. (2015) Fibroadenoma with an Unexpected Lobular Carcinoma in Situ: A Case Report and Review of the Literature. Oncology Letters, 10, 1397-1401. https://doi.org/10.3892/ol.2015.3488

[31] Dupont, W.D., Page, D.L., Parl, F.F., Vnencak-Jones, C.L., Plummer, W.D., Rados, M.S., et al. (1994) Long-Term Risk of Breast Cancer in Women with Fibroadenoma. The New England Journal of Medicine, 331, 10-15. https://doi.org/10.1056/NEJM199407073310103

[32] Noguchi, S., Motomura, K., Inaji, H., Imaoka, S. and Koyama, H. (1993) Clonal Analysis of Fibroadenoma and Phyllodes Tumor of the Breast. Cancer Research, 53, 4071-4074.

[33] McCulloch, R.K., Sellner, L.N., Papadimitrou, J.M. and Turbett, G.R. (1998) The Incidence of Microsatellite Instability and Loss of Heterozygosity in Fibroadenoma of the Breast. Breast Cancer Research and Treatment, 49, 165-169. https://doi.org/10.1023/A:1005930429002 